\title{
PENGARUH ETIKA DAN KINERJA TENAGA KESEHATAN TERHADAP PEMBERIAN PELAYANAN KESEHATAN PASIEN DI PUSKESMAS MADISING NA MARIO KOTA PAREPARE
}

\section{Effect Of Ethics And Performance Of Health Workers On Giving Patient Health Services at Madising Na Mario Health Center Parepare City}

\author{
Fadillah Rijal, H. Muhammad Siri Dangnga, Usman, Niar Novitasari \\ (Program Studi Kesehatan Masyarakat Fakultas Ilmu Kesehatan Universitas \\ Muhammadiyah Parepare) \\ (fadillahrijal234@gmail.com)
}

\begin{abstract}
ABSTRAK
Pelayanan kesehatan untuk masyarakat merupakan hak asasi manusia yang harus dilaksanakan negara. Pemerintah harus mampu memberikan perlakuan yang sama kepada warganya dalam pelayanan kesehatan maupun pelayanan publik lainnya. Dalam penyelenggaraan pelayanan kesehatan, masyarakat dengan status ekonomi lebih tinggi mempunyai akses untuk memenuhi tingkat kepuasan pasien. Sebaliknya, selama pelayanan kesehatan tidak memenuhi tingkat kepuasaan pasien, maka tingkat kesesuaian akan rendah, mengakibatkan puskesmas akan ditinggalkan oleh masyarakat, kedua adalah faktor adanya perubahan (transisi). Dengan demikian, kedudukan dan peran pelayanan puskesmas sangatlah penting untuk dilaksanakan. Tujuan penelitian adalah, untuk mengetahui Pengaruh Etika dan Kinerja Tenaga Kesehatan terhadap Pemberian Pelayanan Kesehatan Pasien di Puskesmas Madising Na Mario Kota Parepare. Penelitian ini menggunakan metode penelitian deskriptif analitik dengan pengambilan sampel secara accidental sampling dengan menggunakan kuesioner sebanyak 100 responden. Hasil penelitian ini menunjukkan ada pengaruh Etika Tenaga Kesehatan terhadap Pemberian Pelayanan Kesehatan di Puskesmas Madising Na Mario Kota Parepare, dengan nilai p (value) = 0,036 <0,05 dan Kinerja Tenaga Kesehatan ada pengaruh terhadap Pemberian Pelayanan Kesehatan di Puskesmas Madising Na Mario Kota Parepare dengan nilai $\mathrm{p}$ (value) $=0,047<0,05$. Mengingat akan pentingnya kesehatan bagi tiap waga masyarakat, olehnya itu tiap sarana pelayanan kesehatan mampu menjalin kerjasama yang baik dengan masyarakat sekitar dalam rangka memberikan pelayanan kesehatan yang optimal.
\end{abstract}

Kata Kunci : Pengaruh etika, kinerja tenaga kesehatan, pemberian pelayanan kesehatan

\section{ABSTRACT}

Health services for the community are human rights that must be implemented by the state. The government must be able to provide equal treatment to its citizens in health services and other public services. In the implementation of health services, people with higher economic status have access to meet the level of patient satisfaction. Conversely, as long as the health service does not meet the patient's satisfaction level, the level of suitability will be low, resulting in the puskesmas being abandoned by the community, the second is the factor of change (transition). Thus, the position and role of the puskesmas service is very important to be implemented. The aim of the study was to determine the effect of ethics and performance of health workers on the provision of patient health services at the Madising Na health center Mario Parepare City. This study uses descriptive analytic research method with sampling by accidental 
sampling using a questionnaire of 100 respondents. The results of this study indicate that there is an influence of the Ethics of Health Workers on the Delivery of Health Services at Madising Na Health Center Mario Parepare City, with a value of $p$ (value) $=0.036<0.05$ and the Performance of Health Workers is an influence on the Giving of Health Services at the Madising $\mathrm{Na}$ health center Mario Parepare City with $p$ value (value) $=0.047<0.05$. Considering the importance of health for each community member, by that each health service facility is able to establish good cooperation with the surrounding community in order to provide optimal health services.

Keywords: Effect of ethics, performance of health workers, giving health services 


\section{PENDAHULUAN}

Puskesmas sebagai pusat pelayanan kesehatan mempunyai dua fungsi, yaitu fungsi pelayanan publik dan fungsi pelayanan klinis atau medikal. Indikasi dalam pemberian pelayanan di puskesmas dapat tercermin dari persepsi pasien atas layanan kesehatan yang diterima. Dari persepsi ini, pasien dapat memberikan penilaian tentang etika dan kinerja tenaga kesehatan dalam pemberian pelayanan. Seperti yang tercantum dalam Undangundang 1945 pasal 23 ayat (1) menyatakan bahwa harus memenuhi ketentuan kode etik, standar profesi, hak pengguna pelayanan kesehatan, standar pelayanan, dan standar prosedur operasional. ${ }^{1}$

Etika adalah kode perilaku yang memperhatikan perbuatan yang baik bagi kelompok tertentu dan prinsip bagi perbuatan yang benar. Etika yang berhubungan dengan hal yang baik dan hal tidak baik dengan kewajiban moral. Karena etika mempunyai tanggung jawab moral, menyimpang dari kode etik berarti tidak memiliki perilaku yang baik dan tidak memiliki moral yang tidak baik. ${ }^{2}$

Kesehatan merupakan suatu bagian terpenting dari kesejahteraan masyarakat. Kesehatan juga merupakan salah satu kebutuhan dasar manusia di samping adanya sandang, pangan, dan papan. Dengan didasari berkembangnya, pelayanan kesehatan dewasa ini, untuk memahami etika kesehatan merupakan bagian terpenting dari kesejahteraan masyarakat serta merupakan tuntunan yang dipandang semakin perlu, karena etika kesehatan merupakan suatu pedoman yang menjadi acuan dalam tindakan melayani para pasien.

Tenaga kesehatan dalam laporan perencanaan kebutuhan sumber daya manusia kesehatan Puskesmas Madising $\mathrm{Na}$ Mario Kota Parepare Kategori Rawat Inap Kawasan Perkotaan Tahun 2018 sebanyak 86 tenaga kesehatan yang merupakan tenaga profesional, selalu menerapkan etika dalam sebagian besar aktifitas sehari-hari. Etika yang merupakan suatu norma perilaku atau biasa disebut dengan asas moral, sebaiknya selalu dijunjung tinggi dalam kehidupan bermasyarakat kelompok manusia. Etika yang berlaku dimasyarakat modern saat ini adalah etika terapan (applied ethics) yang biasanya menyangkut suatu profesi, dimana didalamnya membicarakan tentang pertanyaan-pertanyaan etis dari suatu individu yang terlibat. Sehingga pada masing-masing profesi telah dibentuk suatu tatanan yang dinamakan Kode Etik Profesi.

Kinerja diistilahkan sebagai prestasi kerja (job performance), dalam arti yang lebih luas yaitu hasil kerja secara kualitas, kuantitas dan ketetapan waktu yang dicapai oleh seorang pegawai dalam melaksanakan tugasnya sesuai tanggung jawab yang diberikan. $^{3}$

Perilaku ini memang agak sulit menanganinya, kecuali keasadaran sendiri masing-masing tenaga kesehatan dalam menerapkan, mengaplikasikan, menghayati, memahami, kode etik profesinya. Karena, 
etika profesi lebih bersifat moral, maka kesalahan yang terjadi apabila dilakukan oleh tenaga kesehatan, sanksi yang diberikan bersifat moral dan yang paling dirugikan adalah para kliennya, sehingga untuk menangani pelanggaran yang dilakukan oleh pelaku pelayanan agar tidak terlalu merugikan penggunan pelayanan, dibentuklah suatu majelis kode etik profesi yang berlandaskan pada etika dan hukum yang berlaku.

Sikap dan perilaku tenaga kesehatan yang berbeda-beda, yaitu :

1. Perilaku yang dilakukan telah sesuai, baik terhadap etika dan hukum profesi kesehatan.

2. Perilaku yang dilakukan berlawanan, baik terhadap etika dan hukumprofesi kesehatan.

3. Perilaku yang dilakukan bertentang dengan etika, tetapi sesuai dengan hukum profesi kesehatan.

4. Perilaku yang dilakukan bertentangan dengan hukum tetapi sesuai dengan etika

Sesuai dengan penjelasan sikap dan perilaku tenaga kesehatan, maka dalam memberikan pelayanan yang berkualitas atau pelayanan kesehatan yang prima terhadap masyarakat, seperti halnya pemberian pelayanan publik lainnya, dibutuhkan sikap dan perilaku yang handal dan profesional bagi seluruh Sumber Daya Manusia-Nya. ${ }^{4}$

Kinerja tenaga kesehatan sebagai kemampuan tenaga kesehatan dalam melakukan sesuatu dengan keahlian tertentu. $^{5}$ Sedangkan yang mengatakan bahwa kinerja tenaga kesehatan adalah melakukan suatu kegiatan dan menyempurnakannya sesuai dengan tanggungjawabnya dengan hasil seperti yang diharapkan. ${ }^{6}$

Pelayanan kesehatan untuk masyarakat merupakan hak asasi manusia yang harus dilaksanakan negara. Pemerintah harus mampu memberikan perlakuan yang sama kepada warganya dalam pelayanan kesehatan maupun pelayanan publik lainnya. Dalam penyelenggaraan pelayanan kesehatan, masyarakat dengan status ekonomi lebih tinggi mempunyai akses.

Sebaliknya, selama pelayanan kesehatan tidak memenuhi tingkat kepuasaan pasien, maka tingkat kesesuaian akan rendah, mengakibatkan puskesmas akan ditinggalkan oleh masyarakat, kedua adalah faktor adanya perubahan (transisi). Dengan demikian, kedudukan dan peran pelayanan puskesmas sangatlah penting untuk dilaksanakan. ${ }^{7}$

Puskesmas Madising $\mathrm{Na}$ Mario terletak di wilayah Kecamatan Ujung Kota Parepare, dan merupakan satu dari enam Puskesmas yang ada di Kota Parepare yang dikembangkan menjadi Safe Community dan Brigade Siaga Bencana sejak 9 Januari 2003, yang terletak di wilayah Kecamatan Ujung Kota Parepare mempunyai wilayah kerja sebanyak 2 Kelurahan, yaitu Kelurahan Labukkang dan Kelurahan Mallusetasi. ${ }^{8}$

Berdasarkan survai pengambilan jumlah data awal pasien pada bulan Januari sampai Desember tahun 2017 sebanyak 
38.010 pasien yang sering berkunjung menyatakan bahwa mereka sudah puas terhadap pelayanan yang diberikan di Puskesmas Madising Na Mario Kota Parepare. Kepuasan ini disebabkan karena etika dan kinerja tenaga kesehatan dalam memberikan pelayanan sudah dikatakan cukup baik, terlebih kepada responsiveness tenaga kesehatan dalam menanggapi berbagai keluhan yang dirasakan setiap pasien yang berkunjung dan puskesmas Madising Na Mario Kota Parepare memiliki penghargaan atas prestasinya sebagai Nominal 0 Besar "Lomba Inovasi Lingkup Pemerintah Kota Parepare Tahun 2017"'

Berdasarkan latar belakang yang telah dipaparkan, sehingga penulis tertarik untuk meneliti tentang pengaruh etika dan kinerja tenaga kesehatan terhadap pemberian pelayanan kesehatan pasien, dengan judul "Pengaruh Etika dan Kinerja Tenaga Kesehatan terhadap Pemberian Pelayanan Kesehatan Pasien di Puskesmas Madising Na Mario Kota Parepare.

\section{BAHAN DAN METODE}

Metode penelitian yang dipakai merupakan penelitian deskriptif analitik. Dengan rancangan cross sectional study Populasi dalam penelitian ini sebanyak 100 orang. Penelitian ini menggunakan accidental sampling. Variabel independen dalam penelitian ini adalah etika dan kinerja tenaga kesehatan sedangkan variabel dependennya adalah pemberian pelayanan kesehatan pasien.

Data Primer adalah data yang diperoleh melalui observasi awal dan pembagian kuesioner di Puskesmas Madising Na Mario Kota Parepare. Data Sekunder adalah data yang diperoleh dari Profil Puskesmas Madising Na Mario Kota Parepare, buku dan literatur lain yang berhubungan dengan penelitian ini. Data yang sudah diolah, diuji dengan uji Chi Square nilai signifikan (nila $p$ ), jika nilai $p<$ 0,05 maka $\mathrm{H}_{0}$ ditolak sehingga ada pengaruh etika dan kinerja tenaga kesehatan terhadap pemberian

pelayanan kesehatan pasien di puskesmas Madising Na Mario Kota Parepare.

\section{HASIL}

Distribusi karakteristik responden berdasarkan kelompok umur, jenis kelamin, dan pendidikan pada Tabel 1 menunjukkan distribusi responden menurut umur dari 100 responden. Kelompok umur yang terbanyak ialah 26-35 tahun sebanyak 31 (31,00\%) responden dan terendah 56-65 tahun sebanyak $6(6,00 \%)$ responden. Menurut jenis kelamin menunjukkan bahwa responden terbanyak berjenis kelamin perempuan sebanyak 72 (72,00\%) responden sedangkan menurut tingkat pendidikan yang tertinggi adalah SMA/Sederajat sebanyak 37 $(37,00 \%)$ responden dan yang terendah SD sebanyak $15(15,00 \%)$ responden.

Distribusi responden berdasarkan etika tenaga kesehatan pada Tabel 2 
diperoleh distribusi responden berdasarkan etika tenaga kesehatan yaitu baik sebanyak $88(88,00 \%)$ responden sedangkan kurang baik sebanyak $12(12,00 \%)$ responden.

Distribusi responden berdasarkan kinerja tenaga kesehatan pada Tabel 3 diperoleh distribusi responden berdasarkan kinerja tenaga kesehatan yaitu baik sebanyak $77(77,00 \%)$ responden sedangkan kurang baik sebanyak 23 (23,00\%) responden.

Distribusi responden berdasarkan pemberian pelayanan kesehatan pada Tabel 4 diperoleh distribusi responden berdasarkan pemberian pelayanan kesehatan yaitu memenuhi standar sebanyak 93 (93,00\%) responden sedangkan tidak memenuhi standar sebanyak 7 (7,00\%) responden.

Distribusi Pengaruh etika tenaga kesehatan terhadap pemberian pelayanan kesehatan pasien pada Tabel 5 menunjukkan bahwa etika tenaga kesehatan yang mengatakan baik sebanyak 88 responden $(88,0 \%)$ terdiri dari 84 responden $(84,0 \%)$ yang memenuhi standar pemberian pelayanan kesehatan, dan 4 responden (4,0\%) yang mengatakan kurang memenuhi standar pemberian pelayanan kesehatan. Etika tenaga kesehatan yang mengatakan tidak baik sebanyak 12 responden $(12,0 \%)$ terdiri dari 9 reponden $(9,0 \%)$ yang memenuhi standar pemberian pelayanan kesehatan dan 3 responden (3,0\%) yang kurang memenuhi standar pemberian pelayanan kesehatan. Berdasarkan hasil uji chi-square diperoleh nilai $\mathrm{p}$ (value) $=0,036$ $<\alpha(0,05)$ yang menunjukkan bahwa ada pengaruh etika tenaga kesehatan dengan pemberian pelayanan kesehatan.

Distribusi pengaruh kinerja tenaga kesehatan terhadap pemberian pelayanan kesehatan pada Tabel 6 menunjukkan bahwa kinerja tenaga kesehatan yang mengatakan kinerja baik sebanyak 77 responden $(77,0 \%)$ terdiri dari 74 responden $(74,0 \%)$ yang memenuhi standar pemberian pelayanan kesehatan, dan 3 responden (3,0\%) yang mengatakan kurang memenuhi standar pemberian pelayanan kesehatan. Kinerja tenaga kesehatan yang mengatakan kinerja kurang baik sebanyak 23 responden $(23,0 \%)$ terdiri dari 19 reponden $(19,0 \%)$ yang memenuhi standar pemberian pelayanan kesehatan dan 4 responden $(4,0 \%)$ yang kurang memenuhi standar pemberian pelayanan kesehatan. Berdasarkan hasil uji chi-square diperoleh nilai $\mathrm{p}$ (value) $=$ $0,047<\alpha(0,05)$ yang menunjukkan bahwa ada pengaruh kinerja tenaga kesehatan dengan pemberian pelayanan kesehatan.

\section{PEMBAHASAN}

Etika tenaga kesehatan merupakan seperangkat perilaku anggota profesi tenaga kesehatan kerja dalam hubungannya dengan klien/pasien, teman sejawat dan masyarrakat pekerja serta merupakan bagian dari keseluruhan proses kesehatan kerja ditinjau dari segi norma-norma/nilai-nilai moral. Etika tenaga kesehatan kerja yang didalamnya diikuti adanya kesadaran akan 
pilihan dari pihak manajemen, pihak tenaga kerja dan dari masyarakat sekitarnya.

Tabel 5 menunjukkan bahwa etika tenaga kesehatan yang mengatakan baik sebanyak 88 responden $(88,0 \%)$ terdiri dari 84 responden $(84,0 \%)$ yang memenuhi standar pemberian pelayanan kesehatan, dan 4 responden (4,0\%) yang mengatakan kurang memenuhi standar pemberian pelayanan kesehatan. Etika tenaga kesehatan yang mengatakan tidak baik sebanyak 12 responden $(12,0 \%)$ terdiri dari 9 reponden $(9,0 \%)$ yang memenuhi standar pemberian pelayanan kesehatan dan 3 responden $(3,0 \%)$ yang kurang memenuhi standar pemberian pelayanan kesehatan.

Berdasarkan hasil uji chi-square diperoleh nilai $\mathrm{p}($ value $)=0,036<\alpha(0,05)$, yang menunjukkan bahwa ada pengaruh etika tenaga kesehatan dengan pemberian pelayanan kesehatan.

Berdasarkan interprestasi tersebut dapat dikemukakan bahwa etika tenaga kesehatan berpengaruh secara signifikan terhadap pemberian pelayanan kesehatan di Puskesmas Madising Na Mario Kota Parepare dalam hal ini yang berkaitan adalah:

1. Ikhlas dalam memberikan pertolongan kepada pasien baik secara individu, keluarga, kelompok maupun masyarakat dan semata-mata mengharapkan ridha Allah SWT.

2. Lemah lembut bersedia menerima keterbatasan dan kesulitan yang ada tanpa melampiaskan kenjengkelan terhadap pasien.

3. Berpenampilan yang rapi berarti berpakaian yang rapi, bersih dan elok di pandang mata.

4. Keadilan berarti prinsip keadilan yang dibutuhkan untuk tercapai yang sama dan adil terhadap orang lain.

5. Kebenaran berarti melakukan kegiatan atau tindakan sesuai dengan nilai dan moral dan etika yang tidak bertentangan.

Berdasarkan jawaban responden lebih banyak menjawab baik dibandingkan kurang baik yang menandahkan bahwa etika tenaga kesehatan sudah dikatakan baik khususnya pada keikhlasan dalam melayani pasien di Puskesmas Madising Na Mario Kota Parepare.

Hasil penelitian ini sejalan dengan hasil penelitian dilakukan oleh Purbangkoro Murdijianto 1994, menyatakan bahwa sikap petugas secara pribadi seperti kesopanan, rasa hormat, kesungguhan, keramahan tamahan dari penyedia jasa, tidak membedabedakan dan mendahulukan kepentingan pengguna layanan, dari data yang diperoleh dilokasi penelitian baik perhatian petugas untuk memahami kebutuhan personal terhadap kebutuhan masyarakat. Dan tentunya masyarakat akan merasa puas dalam menyelenggarakan pelayanan dari petugas yang diberikan kepada masyarakat. ${ }^{9}$

Hasil penelitian dilakukan oleh Aras Aira 2016, menyatakan bahwa ada pengaruh yang bermakna antara etika kesehatan dengan pelayanan kesehatan dengan nilai $p$ 
(value) $0,010$. Dimana etika kerja merupakan sikap kpribadian, watak, karakter serta keyakinan atas sesuatu. Etika kerja mempunyai unsur-unsur bersumber dan berkaitan dengan nilai-nilai kejiwaan seseorang, menunjukkan pandangan yang mendarah daging. ${ }^{10}$

Hasil penelitian dilakukan oleh Sofiyya Purnama Sari 2016, menyatakan bahwa ada pengaruh etika perawat pelaksana dengan tingkat kepuasan paien dalam pelayanan didapatkan $\mathrm{p}$ (value) 0,050. Berdasarkan hasil tersebut dapat diketahui bahwa H1 diterima yang berarti ada pengaruh antara etika perawat pelaksana dengan tingkat kepuasan pasien dalam pelayanan di ruang rawat inap kelas III RSD Kalisat Jember. ${ }^{11}$

Semakin baik etika perawat pelaksana, maka tingkat kepuasan pasien dalam pelayanan juga semakin meningkat. Sebaliknya jika perawat pelaksana memiliki etika kurang maka tingkat kepuasan pasien juga semakin menurun. Dapat disimpulkan bahwa etika perawat pelaksana salah satu faktor yang menpengaruhi kepuasan. Tingkat kepuasan sedang dapat menjadi rendah apabila perawat pelaksana tidak memperbaiki etika dalam memberikan pelayanan.

Minat masyarakat dalam mengunjungi Puskesmas Madising Na Mario dipengaruhi oleh etika tenaga kesehatan, mutu pelayanan maupun fasilitas penunjang juga sangat berpengaruh. Etika juga merupakan salah satu indikator yang kerap menjadi tolok ukur dalam tingkat pembangunan suatu instansi kesehatan.

Perilaku ini memang agak sulit menanganinya, kecuali keasadaran sendiri masing-masing tenaga kesehatan dalam menerapkan, mengaplikasikan, menghayati, memahami, kode etik profesinya. Karena, etika profesi lebih bersifat moral, maka kesalahan yang terjadi apabila dilakukan oleh tenaga kesehatan, sanksi yang diberikan bersifat moral dan yang paling dirugikan adalah para kliennya, sehingga untuk menangani pelanggaran yang dilakukan oleh pelaku pelayanan agar tidak terlalu merugikan penggunan pelayanan, dibentuklah suatu majelis kode etik profesi yang berlandaskan pada etika dan hukum yang berlaku.

Kinerja tenaga kesehatan sebagai konsekuensi tuntunan masyarakat terhadap kebutuhan akan pelayanan prima atau pelayanan yang bermutu tinggi. Melalui kinerja tenaga kesehatan, diharapkan dapat menunjukkan konstribusi profesionalnya secara nyata dalam meningkatkan mutu pelayanan kesehatan yang berdampak terhadap pelayanan kesehatan secara umum pada organisasi tempatnya bekerja, dan dampak akhir bermuara pada kualitas hidup dan kesejahteraan masyarakat. Menurut Mangkunegara faktor yang memengaruhi pencapaian kinerja terbagi menjadi dua bagian yaitu faktor kemampuan (ability) dan faktor motivasi (motivation).

Adapun ruang lingkup kinerja tenaga Puskesmas meliputi data dasar 
pelayanan publik, tranparansi, partisipasi dan akuntabilitas :

1. Transparansi

Indikator yang dipakai untuk menilai apakah pelayanan yang diberikan secara transparan dalam arti prosedur layanan, pembiayaan, dan proses pemberian pelayanan.

2. Partisipasi

Indikator yang dipakai untuk menilai apakah dalam memberikan pelayanan, penyedia layanan telah melibatkan masyarakat baik di dalam perencanaan, implementasi dan evaluasi kinerja layanan yang diberikan.

3. Akuntabilitas

Indikator yang dipakai untuk menilai apakah pelayanan publik yang diberikan oleh penyedia layanan telah sesuai dengan standar norma dan nilai yang dianut oleh masyarakat. Akuntabilitas dapat dilihat dari sisi administratif (keuangan), legal, profesional dan moral.

Tabel 6 menunjukkan bahwa kinerja tenaga kesehatan yang mengatakan kinerja baik sebanyak 77 responden $(77,0 \%)$ terdiri dari 74 responden $(74,0 \%)$ yang memenuhi standar pemberian pelayanan kesehatan, dan 3 responden $(3,0 \%)$ yang mengatakan kurang memenuhi standar pemberian pelayanan kesehatan. Kinerja tenaga kesehatan yang mengatakan kinerja kurang baik sebanyak 23 responden $(23,0 \%)$ terdiri dari 19 reponden $(19,0 \%)$ yang memenuhi standar pemberian pelayanan kesehatan dan
4 responden $(4,0 \%)$ yang kurang memenuhi standar pemberian pelayanan kesehatan.

Berdasarkan hasil uji chi-square diperoleh nilai $\mathrm{p}$ (value) $=0,047<\alpha$ $(0,05)$ yang menunjukkan bahwa ada pengaruh kinerja tenaga kesehatan dengan pemberian pelayanan kesehatan.

Berdasarkan interprestasi tersebut dapat dikemukakan bahwa kinerja tenaga kesehatan berpengaruh secara signifikan terhadap pelayanan di Puskesmas Madising Na Mario Kota Parepare dalam hal ini yang berkaitan adalah:

1. Kehandalan (reliability), terdiri dari kemampuan perawat memberikan pelayanan yang dijanjikan dengan tepat dan segera.

2. Daya tanggap (responsiveness), keinginan karyawan untuk membantu pasien dan memberikan pelayanan dengan tanggap.

3. Empati (emphaty), meliputi kemudahan karyawan dalam melakukan hubungan, komunikasi, dan memahami kebutuhan pasien.

4. Jaminan (assurance), mencakup kemampuan, kesopanan dan kejujuran yang dimiliki karyawan, bebas dari bahaya dan resiko.

5. Bukti Langsung (tangibles), meliputi bukti fisik dari jasa, fasilitas fisik, perlengkapan, pegawai dan sasaran komunikasi.

Berdasarkan jawaban responden yang mengatakan tenaga kesehatan dalam memberikan pelayanan sudah tanggap dalam 
menanggapi keluhan-keluhan pasien sehingga beberapa pasien mengatakan kinerja puskesmas sudah baik.

Kinerja tenaga kesehatan merupakan salah satu indikator yang kerap ditelaah dalam mengukur suatu kepuasan masyarakat yang berobat di Puskesmas. Melalui sarana dan prasarana yang memadai kinerja berkontribusi terhadap kepuasan masyarakat. Kinerja tenaga kesehatan sangat berhubungan dengan kesehatan masyarakat menuju yang lebih baik dan optimal.

Hasil penelitian ini sejalan dengan hasil penelitian yang dilakukan oleh Zaini 2004, yang menyatakan ada pengaruh yang bermakna antara kinerja perawat pelaksana dengan kepuasan pasien dengan nilai $p$ (value) 0,008. Dari hasil penelitian didapatkan bahwa kinerja tenaga kesehatan berpengaruh nyata terhadap kepuasan pasien pengguna kartu yankestis dalam pelayanan keperawatan di RSUD Syech Yusuf Kabupaten Gowa, dimana penilaian pelaksanakan kerja pegawai sebaiknya menunjukkan hal-hal yang sudah memuaskan dan menunjukkan hal yang perlu diperbaiki oleh pegawai. ${ }^{12}$

Hasil penelitian dilakukan oleh Kartin Buheli 2015, yang menyatakan ada pengaruh yang signifikan antara kinerja dengan pelaksanaan penerapan perawatan dengan kepuasan pasien dengan nilai $p$ (value) 0,035 . Supervisi pimpinan juga dapat meningkatkan kinerja karyawan, supervisi memberikan kontribusi $87,5 \%$ terhadap kinerja perawat. Dengan demikian semakin baik supervisi terhadap perawat maka semakin baik pula kinerjanya, sebaliknya semakin tidak baik supervisi terhadap perawat maka semakin tidak baik pula kinerjanya. ${ }^{13}$

Hasil penelitian dilakukan oleh Suryanti Kasim 2013, yang mengatakan ada pengaruh yang bermakna antara disiplin waktu dalam pelayanan dengan kinerja tenaga kesehatan dengan nilai $p$ (value) 0.017. Dalam hal ini, untuk meningkatkan kinerja pelayanan kesehatan yang baik, diperlukan disiplin waktu yang baik pula. ${ }^{14}$

Berbeda dengan hasil penelitian yang dilakukan oleh Sri Rahayu 2009, menunjukkan bahwa tidak ada pengaruh kinerja perawat dalam melaksanakan asuhan keperawatan di RSUD Seragen dengan nilai p (value) 0,244. Dari hasil penelitian didapatkan bahwa kinerja tenaga kesehatan tidak berpengaruh pemberian penghargaan sesuai dengan prestasi kerja juga dapat menjadi salah satu faktor pendorong semangat dalam bekerja. ${ }^{15}$

Hasil penelitian yang dilakukan oleh Ahmad Ahid Mudayana 2012, menunjukkan bahwa tidak ada pengaruh kinerja pegawai terhadap beban kerja di Rumah Sakit Nur Hidayah Bantul dengan nilai p (value) 0,066. Dari hasil penelitian didapatkan bahwa besar kecilnya beban kerja tidak akan mempengaruhi kinerja pegaai selama tidak mengalami stress. ${ }^{16}$

Pelayanan diberikan di Puskesmas Madising Na Mario Kota Parepare kepada pasien atau masyarakat berdasarkan hasil 
penelitian baik, sesuai dengan apa yang dirasakan pasien sebagai pengguna jasa pelayanan Puskesmas. Berdasarkan apa yang telah dialami oleh banyak pasien menyebutkan bahwa kinerja tenaga kesehatan di Puskemas Madising Na Mario dikatakan sudah baik oleh pasien dan pasien merasa puas. Kinerja tenaga kesehatan dikelompokkan berdasarkan orientasi pada proses dan hasil, sesuai prosedur, responsivitas, akuntabilitas, dan transparansi sudah diterapkan oleh Puskesmas Madising $\mathrm{Na}$ Mario Kota parepare.

\section{KESIMPULAN DAN SARAN}

Berdasarkan hasil penelitian yang dilakukan di Puskesmas Madising Na Mario Kota Parepare pada tanggal 11 Mei-25 Juli 2018 dapat disimpulkan bahwa ada pengaruh etika dan kinerja tenaga kesehatan terhadap pemberian pelayanan kesehatan pasien di puskesmas Madising $\mathrm{Na}$ Mario Kota

\section{DAFTAR PUSTAKA}

1. Sugiyono. Metode Penelitian Administrasi. Yogyakarta : Graha Ilmu; 2011.

2. Dalami. Pengertian Etika, Jakarta: Trans Info Media; 2010.

3. Mangkunegara. Kinerja Pegawai Mempertimbangkan Kuantitas, Kualitas dan Ketetapan Waktu dalam Bekerja. Jakarta; 2010.

4. Buheli K. Faktor yang mempengaruhi Kinerja Perawat dalam Penerapan proses Keperawatan di RSUD Toto
Parepare. Berdasarkan hasil kesimpulan, Untuk etika tenaga kesehatan meningkatkan lagi dalam menghormati pasien, menghargai kekuatan dan kontribusi mereka yang berbeda, menekankan pentingnya komunikasi yang terbuka dan jujur dan bertanggung jawab yang bertujuan untuk mencegah hasil kesehatan yang merugikan pasien. Diharapkan agar kinerja tenaga kesehatan di Puskesmas Madising Na Mario Kota Parepare tetap dipertahankan untuk menjaga kepuasan pasien, oleh karena itu organisasi harus menambah fasilitas serta tenaga kerja untuk kinerja pelayanan kesehatan akan lebih baik lagi kedepannya. Mengingat akan pentingnya kesehatan bagi tiap warga masyarakat, olehnya itu tiap sarana pelayanan kesehatan mampu menjalin kerjasama yang baik dengan masyarakat sekitar dalam rangka memberikan pelayanan kesehatan yang lebih optimal.

Kabupaten Bone Bolango.Gorontalo; 2015.

5. Sinambela L. Reformasi Pelayanan Publik, Jakarta: PT. Bumi Aksara; 2006.

6. Widodo J. Membangun Birokrasi Berbasis Kinerja, Jakarta: Bayunedai Publishing; 2008.

7. Santoso. Analisis Pengaruh Kualitas Pelayanan, Kepuasaan Pelanggan, Dan Lokasi Terhadap Lokasi Pelanggan. [serial online]; 2010. [Diakses tanggal 03 Mei 2018] at http://eprints.undip.ac.id/26970. 
8. Profil Puskesmas Madising $\mathrm{Na}$ Mario Kota Parepare. Parepare : Profil Kesehatan Puskesmas Madising $\mathrm{Na}$ Mario Kota Parepare; 2017.

9. Murdijianto P. Pengaruh Faktor Sosial Ekonomi dan Fasilitas Umum serta Kesehatan Terhadap Kematian Bayi (Disertasi). Studi Kasus di Kabupaten Jember Jawa Timur. Jember: Laporan Penelitian. Lembaga Penelitian Univeritas Jember; 1994.

10. Aira A. Pengaruh Etika Kerja terhadap Kinerja Manajerial pada Suatu Perangkat Daerah (SKPD) Kabupaten Kampar. Riau; 2016.

11. Sari S P. Etika Tenaga Kesehatan Pelaksana dengan Tingkat Kepuasan Pasien dalam Pelayanan di Ruang Rawat Inap Kelas III RSD Kalisat Jember; 2016.

12. Zaini E. Kinerja tenaga kesehatan berpengaruh nyata terhadap kepuasan pasien pengguna kartu yankestis dalam pelayanan di RSUD Syech Yusuf Kabupaten Gowa; 2004.
13. Buheli K. Faktor yang mempengaruhi Kinerja Perawat dalam Penerapan proses Keperawatan di RSUD Toto Kabupaten Bone Bolango.Gorontalo; 2015.

14. Kasim S. Pengaruh yang bermakna antara disiplin waktu dalam pelayanan kinerja enaga kesehatan; 2013.

15. Rahayu S. Hubungan Antara System Reward Dengan Kinerja Tenaga Kesehatan Dalam Melaksanakan Asuhan Keperawatan di RSUD Sragen; 2009: 2(2) : 51-56.

16. Mudayana A, A. Hubungan Beban Kerja dengan Kinerja Karyawan di Rumah Sakit Nur Hidayah Bantul. Bantul; 2012.

17. Usman. Analisis Kinerja Tenaga Kesehatan pada Puskesmas Lapadde Kota Parepare. Jurnal Media Kesehatan Masyarakat Indonesia Fakultas Kesehatan Masyarakat Universitas Hasanuddin Makassar; 2016 : 12(1) : 21-28 


\section{LAMPIRAN}

Tabel 1. Distribusi Karakteristik Responden Berdasarkan Kelompok Umur, Jenis Kelamin, dan Pendidikan di Puskesmas Madising Na Mario Kota Parepare Tahun 2018

\begin{tabular}{ccc}
\hline Karakteristik responden & Frekuensi (f) & Persentase (\%) \\
\hline Kelompok umur (Tahun) & 13 & 13.00 \\
$17-25$ & 31 & 31.00 \\
$26-35$ & 17 & 17.00 \\
$36-45$ & 25 & 25.00 \\
$46-55$ & 6 & 6.00 \\
$56-65$ & 8 & 8.00 \\
$66-75$ & 28 & \\
Jenis kelamin & 72 & 28.00 \\
Laki-laki & & 72.00 \\
Perempuan & 15 & 15.00 \\
Pendidikan & 28 & 28.00 \\
SD & 37 & 37.00 \\
SMP & 20 & 20.00 \\
SMA/Sederajat & 100 & 100.00 \\
S1 & &
\end{tabular}

Sumber : Data Primer Tahun 2018

Tabel 2. Distribusi Responden Berdasarkan Etika Tenaga Kesehatan di Puskesmas Madising Na Mario Kota Parepare Tahun 2018

\begin{tabular}{ccc}
\hline Etika Tenaga Kesehatan & Jumlah (n) & Persentase (\%) \\
\hline Baik & 88 & 88,00 \\
Kurang Baik & 12 & 12,00 \\
\hline Total & 100 & 100,00 \\
\hline
\end{tabular}

Sumber : Data Primer Tahun 2018

Tabel 3. Distribusi Responden Berdasarkan Kinerja Tenaga Kesehatan di Puskesmas Madising Na Mario Kota Parepare Tahun 2018

\begin{tabular}{ccc}
\hline Kinerja Tenaga Kesehatan & Jumlah (n) & Persentase (\%) \\
\hline Baik & 77 & 77,00 \\
Kurang Baik & 23 & 23,00 \\
\hline Total & 100 & 100,00 \\
\hline
\end{tabular}

Sumber : Data Primer Tahun 2018 
Tabel 4. Distribusi Responden Berdasarkan Pemberian Pelayanan Kesehatan di Puskesmas Madising Na Mario Kota Parepare Tahun 2018

\begin{tabular}{ccc}
\hline Pemberian Pelayanan Kesehatan & Jumlah (n) & Persentase (\%) \\
\hline Memenuhi Standar & 93 & 93,00 \\
Tidak Memenuhi Standar & 7 & 7,00 \\
\hline Total & 100 & 100,00 \\
\hline
\end{tabular}

Sumber : Data Primer Tahun 2018

Tabel. 5 Pengaruh Etika Tenaga Kesehatan terhadap Pemberian Pelayanan Kesehatan Pasien di Puskesmas Madising Na Mario Kota Parepare Tahun 2018

\begin{tabular}{|c|c|c|c|c|c|c|c|}
\hline \multirow{3}{*}{$\begin{array}{l}\text { Etika } \\
\text { Tenaga } \\
\text { Kesehatan }\end{array}$} & \multicolumn{4}{|c|}{ Pemberian Pelayanan Kesehatan } & & & \multirow{3}{*}{$\mathrm{p}$ value } \\
\hline & \multicolumn{2}{|c|}{$\begin{array}{l}\text { Memenuhi } \\
\text { Standar }\end{array}$} & \multicolumn{2}{|c|}{$\begin{array}{c}\text { Kurang } \\
\text { Memenuhi } \\
\text { Standar }\end{array}$} & \multicolumn{2}{|c|}{ Total } & \\
\hline & $\mathrm{N}$ & $\%$ & $\mathrm{n}$ & $\%$ & $\mathrm{n}$ & $\%$ & \\
\hline Baik & 84 & 84,0 & 4 & 4,0 & 88 & 88,0 & \\
\hline Tidak Baik & 9 & 9,0 & 3 & 3,0 & 12 & 12,0 & 0,036 \\
\hline Total & 93 & 93,0 & 7 & 7,0 & 100 & 100,0 & \\
\hline
\end{tabular}

Sumber : Data Primer Tahun 2018

Tabel. 6 Pengaruh Kinerja Tenaga Kesehatan terhadap Pemberian Pelayanan Kesehatan Pasien di Puskesmas Madising Na Mario Kota Parepare Tahun 2018

\begin{tabular}{|c|c|c|c|c|c|c|c|}
\hline \multirow{3}{*}{$\begin{array}{l}\text { Kinerja } \\
\text { Tenaga } \\
\text { Kesehatan }\end{array}$} & \multicolumn{4}{|c|}{ Pemberian Pelayanan Kesehatan } & \multirow{2}{*}{\multicolumn{2}{|c|}{ Total }} & \multirow{3}{*}{$\mathrm{p}$ value } \\
\hline & \multicolumn{2}{|c|}{$\begin{array}{l}\text { Memenuhi } \\
\text { Standar }\end{array}$} & \multicolumn{2}{|c|}{$\begin{array}{c}\text { Kurang } \\
\text { Memenuhi } \\
\text { Standar }\end{array}$} & & & \\
\hline & $\mathrm{N}$ & $\%$ & $\mathrm{~N}$ & $\%$ & $\mathrm{~N}$ & $\%$ & \\
\hline Kinerja Baik & 74 & 74,0 & 3 & 3,0 & 77 & 77,0 & \multirow{3}{*}{0,047} \\
\hline $\begin{array}{c}\text { Kinerja } \\
\text { Kurang Baik }\end{array}$ & 19 & 19,0 & 4 & 4,0 & 23 & 23,0 & \\
\hline Total & 93 & 93,0 & 7 & 7,0 & 100 & 100,0 & \\
\hline
\end{tabular}

Sumber : Data Primer Tahun 2018 